\title{
Correction to: Estimation of component reliability from superposed renewal processes by means of latent variables
}

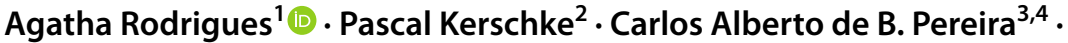 Heike Trautmann ${ }^{5} \cdot$ Carolin Wagner $^{5} \cdot$ Bernd Hellingrath $^{5} \cdot$ Adriano Polpo $^{6}$}

Accepted: 22 July 2021 / Published online: 21 August 2021

(c) Springer-Verlag GmbH Germany, part of Springer Nature 2021

\section{Correction to: Computational Statistics https://doi.org/10.1007/s00180-021-01124-0}

In the original publication of the article, the affiliation of author Heike Trautmann was incorrectly published. This erratum corrects the same.

The original article has also been corrected.

Publisher's Note Springer Nature remains neutral with regard to jurisdictional claims in published maps and institutional affiliations.

The original article can be found online at https://doi.org/10.1007/s00180-021-01124-0.

Agatha Rodrigues

agatha.rodrigues@ufes.br

1 Department of Statistics, Federal University of Espírito Santo, Vitória, ES, Brazil

2 Big Data Analytics in Transportation, Technical University Dresden, 01062 Dresden, Germany

3 Institute of Mathematics and Statistics, University of São Paulo, São Paulo, SP, Brazil

4 Institute of Mathematics, Federal University of Mato Grosso do Sul, Campo Grande, MS, Brazil

5 Information Systems and Statistics, University of Münster, 48149 Münster, Germany

6 Western Australia University, Perth, Australia 